\title{
NIETZSCHE EN DELEUZE: HACIA UNA GENEALOGÍA DEL PENSAMIENTO CRÍTICO
}

\author{
Diego SÁNCHEZ MECA \\ UNED
}

\section{El interés de Deleuze por Nietzsche}

El interés de Deleuze por la obra de Nietzsche se debe, entre otras razones, a que ve en él a uno de los filósofos que con mayor eficacia crítica contradice la concepción clásica del pensamiento como búsqueda de la verdad y como ejercicio de amor a la verdad. Nietzsche se opone a la tradición filosófica que considera que el pensamiento quiere y ama la verdad, de la que nos vemos alejados por la acción de fuerzas extranias al pensamiento (procedentes del cuerpo, de las pasiones, de los intereses, etc.). Esta tradición cree, en consecuencua, que «basta con un método para pensar bien, para pensar lo verdadero" (NP, 118) ${ }^{1}$.

El principal reproche de Nietzsche a esta concepción del pensamiento es que "no hace referencia nunca a las fuerzas reales que intervienen en el pensamiento ni refiere el pensamiento mismo a las fuerzas reales que supone en cuanto pensamiento» (NP, 118). En su obra Proust y los signos (1964), elaborada casi simultáneamente al espléndido estudio dedicado a Nietzsche y publicada dos años después, Deleuze destaca hasta qué punto las sensaciones de dolor y de placer, las variaciones de intensidad de estas sensaciones, el efecto de un encuentro fortuito con imágenes o signos, son capaces de poner en funcionamiento el pensamiento y la reflexión. Por tanto no es cierto que todas

1 Citamos las obras de DELEUZE de acuerdo con las siguientes ediciones y abreviaturas: Nietzsche et la philosophie, París, PUF, 1962 = NP; Marcel Proust et les signes, París, PUF, 1964 = PS; Le Bergsonisme, Paris, PUF, 1966 = LB; Difference et répetition, París, PUF, 1968 = DR; Logique du sens, París, Minuit, 1969 = LS. 
estas fuerzas "extrañas al pensamiento" nos aparten de la verdad, sino que son ellas los determinantes esenciales para su búsqueda y revelación. En la obra de Proust es frecuente encontrar situaciones en las que la verdad se delata antes de dejarse descubrir. Muchos de sus personajes traicionan un secreto, celosamente guardado, por un gesto que no viene a cuento, una palabra fuera de lugar, un comportamiento que contrasta con los hábitos cotidianos de esa persona. Esto lleva a Deleuze a concluir que, "a la idea filosófica de método, Proust opone la doble idea de la coacción y del azar. La verdad depende de un encuentro con algo que nos obliga a pensar y a buscar la verdad. El azar de los encuentros, la presión de la coacción son dos temas fundamentales en Proust. Y lo que constituye el objeto de un encuentro, o sea, lo que ejerce sobre nosotros esa violencia, es el signo" (PS, 33).

La idea central de la temática de la genealogía en Nietzsche es que el pensamiento nunca piensa por sí mismo, ni encuentra por sí mismo la verdad (NP, 118), sino que está siempre condicionado y determinado por relaciones de fuerzas que se establecen con la mediación del cuerpo. Por tanto, la pregunta "¿Qué es lo verdadero?" debe quedar sustituída por estas otras: "¿Quién busca la verdad?", "¿Qué quiere quien afirma tal o cual cosa como verdad?". Pues «pensar depende de las fuerzas que se apoderan del pensamiento. Pensar como actividad es siempre una segunda potencia del pensamiento, no el ejercicio natural de una facultad, sino un acontecimiento extraordinario en el pensamiento mismo y por el pensamiento mismo" (NP, 123).

Y al oponerse así a la imagen dogmática del pensamiento, propia de la tradición filosofica ${ }^{2}$, Nietzsche reivindica todo un nuevo concepto de filosofia como ejercicio práctico de valoración y de interpretación, filosofía como crítica orientada a fijar el sentido y el valor que son determinados por la fuerza y por relaciones de fuerza: "Pensar es juzgar y juzgar es valorar e interpretar, es crear valores. El problema del juicio es el problema de la justicia y de la jerarquía de las fuerzas» (NP, 107). Es el programa filosófico que Nietzsche entiende como original de los filósofos presocráticos y que se diluye cuando la filosofía se convierte en teoría y en metafísica por obra, sobre todo, de Sócrates y de Platón.

2 Cfr. DR, 169-217 y NP, 118-123; también FoucaulT, M., "Theatrum philosophicum", en Critique 1970 (282), págs. 885-908. 
A Deleuze le atrae, pues, esta perspectiva crítica de Nietzsche y, decidido a desarrollar las ambiciosas propuestas que representa, emprende un brillante análisis de la obra nietzscheana - que, a partir de 1962 (año en que se publica Nietzsche et la philosophie), sigue incansable a lo largo de toda su trayectoria intelectual--, en busca de respuestas a los distintos y decisivos problemas que se plantean. Concretamente, tratará de determinar: 1) Cuáles son las condiciones de la interpretación que resultan de una revisión de la concepción nietzscheana de la voluntad de poder; 2) Cómo el sentido despliega la multiplicidad de mundos incluídos en los signos y cómo se explica la identidad a partir de la repetición de la diferencia, desde una reinterpretación de la idea nietzscheana del eterno retorno; 3) Cómo entender el nuevo pensamiento crítico como pensamiento afirmativo, tomando como base la tematización nietzscheana de lo trágico.

\section{La reinterpretación de la voluntad de poder como elemento genético y diferenciador de la fuerza}

Para Nietzsche, pensar es interpretar. Al conocimiento verdadero, situado por la tradición metafísica como contenido y meta del filosofar, él contrapone la práctica filosófica consistente en la interpretación y valoración de lo que pretende hacerse pasar por verdadero. Lo primero que hay que cuestionar, por tanto, es el dualismo metafísico de apariencia y realidad, sensible e inteligible, en el que se basa la concepción de la verdad como adecuación. Es lo que Nietzsche hace introduciendo la noción de sentido que se atribuye a un fenómeno. Contra la búsqueda metafísica de la verdad inteligible, situada más allá de lo sensible y temporal, Nietzsche desarrolla los conceptos de sentido y valor que permiten detectar, tras cualquier verdad o valor que se pretenden válidos y universales, una valoración que procede del modo de ser en el mundo de quienes los afirman o asumen: «El sentido de algo está en su relación con la fuerza que se apodera de éh y, por tanto, el valor de algo está en la jerarquía de las fuerzas que se expresan en la cosa como fenómeno complejon (NP, 31).

La introducción de estas nociones de sentido y valor tienen, inmediatamente, algunas importantes consecuencias: 1) Las esencias, de las que habla la filosofia tradicional, no son otra cosa que el sentido que es afirmado por una voluntad como afirmación de su potencia y de su diferencia de fuerza: «El sentido de los signos es una esencia afirmada en toda su potencia» (PS, 64). La 
noción de potencia adopta aquí un valor particular, pues, caracterizada por su potencia $\longrightarrow$ sea por una determinada virtualidad e intensidad-, la potencia entra en una relación de identidad con el signo y con el sentido. Las esencias deberán ser consideradas en su potencia para expresarse en una multiplicidad de signos y ser reveladas por ellos; 2) El sentido es siempre múltiple, porque la característica de la fuerza que lo afirma es la pluralidad y la diferencia respecto de las otras fuerzas; 3) El sentido de un mismo fenómeno cambia cuando cambian las fuerzas que se apoderan de él.

La voluntad de poder es, en consecuencia, el elemento que condiciona con su potencia el sentido de los fenómenos, elemento diferenciador del valor de los valores y, para ello, previamente, el elemento diferenciador de la fuerza: «La voluntad de poder es el elemento del que derivan la diferencia de cantidad de las fuerzas puestas en relación y, a la vez, la cualidad que, en función de esta relación, caracteriza a cualquier fuerza" (NP, 84). Es decir, en el planteamiento de Nietzsche, la voluntad de poder es un principio creador pero inseparable de una tipología pluralista, «inseparable de los casos particulares en los que se determina" (NP, 130). Esto se aclara y precisa cuando Nietzsche señala al cuerpo como "campo de batalla» de la voluntad de poder. El cuerpo es un compuesto de una multiplicidad de fuerzas irreductibles. De ellas unas son dominantes o activas, y otras son dominadas o reactivas. Actividad y reactividad son las cualidades de una determinada relación de fuerzas producida en sus continuos encuentros al azar. Y esta cualidad no es otra cosa que el producto de su cantidad, o sea, de la diferencia de cantidad de unas fuerzas frente a otras. Expresados así los términos del planteamiento, puede entenderse entonces en qué sentido Nietzsche define la voluntad de poder como voluntad de querer afirmar la propia diferencia de cantidad de fuerza, siendo el análisis genealógico el método o procedimiento que él propone para descubrir ese uelemento diferencial de los valores del que procede su valor" (NP, 25), o sea el tipo de voluntad de poder que los pone o afirma.

Presentándose, pues, como una nueva filosofía de la voluntad, la de Nietzsche se separa, sin embargo, así radicalmente de la manera en que la voluntad había sido tradicionalmente comprendida como "deseo de poder", "querer ejercer el dominio". A pesar de diferencias inconmensurables en sus planteamientos, pensadores como Hobbes, Hegel o Schopenhauer coinciden en ver la voluntad como una energía única que, en cuanto potencia esencialmente destructiva, es necesario negar. Hobbes, el filósofo del bellum omnium contra omnes, considera precisa la voluntaria sumisión a un soberano (conteni- 
do del pacto social) como único modo de impedir la guerra generalizada. La opinión de Hegel se expresa de modo suficientemente claro en su tematización de la relación dialéctica entre duefio y esclavo. Y Schopenhauer ve, por su parte, en la voluntad única y universal el origen del egoísmo y de la lucha por la existencia, proponiendo una ética de la renuncia y de la negación de la vida. Nietzsche rechaza todas estas teorías de la voluntad que acaban negándola y dan origen así o refuerzan el resentimiento y la conciencia de culpa. Frente a ellas señala, principalmente, tres cosas: 1) En primer lugar, que la voluntad no es una fuerza unitaria, sino relaciones de fuerzas enfrentadas y pugnando unas contra otras por imponer su propia diferencia de fuerza. El querer único de la metafísica debe disgregarse en una pluralidad de fuerzas en lucha entre sí, que se afirman como tales midiéndose antagonísticamente; 2) En segundo lugar, la voluntad como voluntad de poder no es un "querer el poder" que surge de una carencia de fuerza a la que se quiere suplir mediante la adquisición del poder, sino que tiene como base su propia afirmatividad. $O$ sea, lo que la voluntad quiere no es el poder, sino que es la potencia (la multiplicidad afirmativa) la que se quiere a través de la voluntad de poder: "La potencia es lo que quiere en la voluntad de poder. La potencia es, en la voluntad, el elemento genético y diferenciador. Por ello la voluntad de poder es esencialmente creadora» (NP, 96-97). Voluntad de poder es, en definitiva, reconocer y querer lo múltiple; 3) En tercer lugar, la negación de la voluntad a la que conducen las concepciones de la tradición filosófica y que nutren los ideales ascéticos, es paralela al hiperdesarrollo de la conciencia como instancia de negación, de autolimitación y de represión: "La conciencia es esencialmente reactiva” (NP, 47). "¿Qué es activo? Tender al poder» (NP, 48). La conciencia pertenece, pues, para Nietzsche, a las fuerzas reactivas y es siempre expresión de ellas.

E invirtiendo así la concepción tradicional de la voluntad y su valoración, es como cree Nietzsche que se supera el nihilismo de la metafísica occidental y su concepción dogmática del conocimiento como representación. Por eso, según Deleuze, Nietzsche debe ser reconocido como el verdadero punto de viraje crítico, en la modernidad, respecto a la filosofía clásica, y no Kant. Para Deleuze, Nietzsche es un descendiente a la vez que un rival de Kant, al hacer de su filosofia «una transformación radical del kantismo y una reinvención de la crítica que Kant traicionó en el momento mismo de emprenderla» (NP, 87), al replegarla sobre la dialéctica y sobre el conocimiento de lo verdadero, que continuaba siendo asumido como el problema fundamental de la filosofía y que hacía lógicos y naturales, por tanto, los posteriores desarrollos idealistas 
postkantianos. Lejos, pues, de representar el cumplimiento del nihilismo europeo, la concepción nietzscheana de la voluntad de poder constituye un nuevo inicio para el pensamiento, que "debe sustituir a la vieja metafísica, destruirla y superarla" (NP, 95).

En conclusión, la voluntad de poder es el elemento que interpreta, o sea, el elemento que determina la fuerza que da sentido a la cosa, el elemento que valora o que confiere valor a la cosa como factor diferenciador. El sentido y el valor derivan, en última instancia, de la voluntad de poder como relación de fuerzas. Su esencia la constituye una diferencia que es «el objeto de una afirmación práctica inseparable de la esencia y constitutiva de la existencias (NP, 33). Esta no es, claro está, la diferencia hegeliana: «La dialéctica hegeliana es reflexión sobre la diferencia, pero invierte su imagen" (NP, 70). Deleuze opone con cierto detenimiento, a lo largo de su Nietzsche et la philosophie, la diferencia nietzscheana a la de Hegel, detallando cómo «el sí de Nietzsche se opone al no dialéctico, la afirmación dionisiaca a la negación dialéctica, la diferencia a la contradicción dialéctica" (NP, 10). Su tesis es que la voluntad de poder es el principio de la sintesis de las fuerzas, pero una síntesis que, en vez de anularlas (Aufhebung), subraya su diferencia al establecer su jerarquía y cualificar diferenciadamente a cada una de ellas. De ahí que, para Deleuze, el interés de la operación de Nietzsche consista, sobre todo, en uhaber descubierto, en el corazón de la síntesis, la reproducción de lo diverso" (NP, 87). El concepto con el que Nietzsche piensa de manera original y revolucionaria esa modalidad de síntesis de las fuerzas es su concepto del eterno retorno.

\section{El eterno retorno de lo semejante y la repetición como potencia de la diferencia}

También en lo que se refiere a esta idea del eterno retorno es preciso distinguir la peculiaridad del pensamiento nietzscheano frente a lo que ordinariamente se ha creído que significaba la concepción antigua del tiempo que este concepto implica. En Nietzsche, según Deleuze, el eterno retorno no es pensamiento de lo idéntico, sino, al contrario, pensamiento sintético, pensamiento de lo absolutamente diferente. Es decir, «no es lo mismo y lo uno lo que retornan en el eterno retorno, sino que el retorno es él mismo lo uno que se dice sólo de lo diverso y de lo que difiere" (NP, 130). Y en este sentido, el eterno retorno es precisamente lo que garantiza la diferencia a través de su repetición. 
La dificultad que entraña comprender esto puede verse superada mediante un determinado estudio de las obras de arte que permite esbozar las líneas de fuerza de los problemas fundamentales. Si se atiende a las repeticiones, que son inherentes a las obras de arte, y nos concentramos en la noción de estilo, se puede tomar conciencia con facilidad de lo que significa concretamente, para Deleuze, esa unidad fundamental del sentido y las esencias como potencias de la diferencia que hacen retornar, en cada una de las obras, una y otra vez, las mismas relaciones de fuerza. Marcel Proust parece estar pensando en esta misma relación de la diferencia y la repetición cuando, refiriéndose a la sonata de Vinteuil, comenta: "Tal o cual frase de la sonata retornaba la misma una y otra vez, pero cada vez cambiada sobre un ritmo o un acompañamiento diferente; la misma y, sin embargo, otra, como retornan las cosas en la vida ${ }^{3}$ ". Es decir, lo que retorna aquí, una y otra vez, no es una identidad, una idea platónica pura y siempre igual a sí misma, sino algo concreto, unos sonidos, unas intensidades sonoras, unas separaciones rítmicas, una distribución en el tiempo de las diferencias intensivas no contradictorias, diferentes "modalidades", etc. etc. Pero, al mismo tiempo, lo que se repite en cada retornar es el todo, o sea, el mundo de esas intensidades que se diferencian sin cesar. La diferencia es indisociable de estos dos tipos distintos de repetición, la de lo diferente y la de lo mismo, que se sintetizan en el estilo: "La una es material, la otra espiritual; la una es repetición de instantes o de elementos sucesivos independientes; la otra es una repetición del todo, a niveles diversos coexistentes... La una está desnuda, la otra vestida; la una es de partes, la otra del todo; la una de sucesiones, la otra de coexistencias; la una actual, la otra virtual; la una horizontal, la otra vertical” (DR, 114; Cfr. también DR, 367).

¿Qué es, pues, lo que en las obras de arte marca la diferencia, la esencia que diversifica, que se diversifica y a la vez se repite como tal, idéntica a sí misma como potencia de diferenciación? Deleuze responde: el estilo: “El estilo no es el hombre, el estilo es la esencia misma" (PS, 62). Una esencia, sin embargo, que se revela en lo que los cuerpos muestran, es decir, no como algo que se descubre en cuanto verdad en el sentido platónico del término, sino como algo que se manifiesta en cuanto mero simulacro. La revelación de la esencia se produce en la obra de arte a través de una unidad del signo, de la esencia y del sentido como diferencia en acto, como estilo que se repite y diversifica multi-

3 Proust, M., La Prisonnière, París, Gallimard, 1954, pág. 259. 
plicando los signos inmateriales, los encuentros y las rupturas. Pero el estilo es pura apariencia. Esta es la razón de por qué el estilo funciona como verdadero proceso de individuación: «El arte nos da la verdadera unidad: unidad de un signo y de su sentido espiritualn (PS, 52). Y de este modo se puede entender mejor ahora la relación que Nietzsche establece entre estilo y voluntad de poder, al reparar en la identidad de la esencia y el sentido definido como afirmación de la potencia y de la diferencia, o sea el sentido como esencia afirmada en su capacidad o potencia para expresarse en una multiplicidad de signos y ser revelada por ellos.

En conclusión, el retorno de lo semejante no es más que un efecto de la repetición considerada como potencia de la diferencia: «Siempre es en el mismo movimiento donde la repetición comprende la diferencia... y donde debe recibir un principio positivo del que resulte la repetición material indiferente" (DR, 370); "La repetición no es nunca repetición de lo mismo, sino siempre de lo diferente como tal, teniendo la diferencia en sí misma por objeto la repetición" (DR, 330).

En definitiva, el eterno retorno no es otra cosa, pues, que "la síntesis del tiempo y de sus dimensiones” (NP, 82), o sea, el ser del devenir. Y esto, en relación a las concepciones metafísicas del pensamiento tradicional, entrana dos consecuencias de enorme trascendencia crítica: 1) Por un lado, el eterno retorno, como ser del devenir, representa el cuestionamiento más extremo de la representación clásica de la duración, del tiempo y de la relación fundamental que mantienen con la memoria, así como con la separación habitual de pasado, presente y futuro. Con la concepción del eterno retorno se deja de considerar el tiempo a partir de las nociones estáticas y abstractas de presente, pasado y futuro, y se aborda en su dinamismo concreto considerando las nebulosas, los mundos y los vectores que se expresan en él bajo la forma de líneas distintas. Estas líneas constituyen series: «El tiempo mismo es serial» (PS, 108); 2) Por otro lado, el eterno retorno arruina la filosofía clásica de la representación porque arruina todo pensamiento del origen y del modelo: «El eterno retorno, tomado en su sentido estricto, significa que cada cosa sólo existe retornando, copia de una infinidad de copias que no dejan subsistir ni original ni origen... Lo que es o retorna no tiene ninguna identidad previa y constituída:

4 Deleuze, G., “Conclusions sur la volonté de puissance et l'éternel retour», en AAVV, Nietzsche. Cahiers de Royaumont, París, Minuit, 1987, pág. 284. 
la cosa se reduce a la diferencia que la separa y a todas las diferencias implicadas en ella, por las cuales pasa. Por ello, se dice del eterno retorno que es paródico, porque califica lo que hace ser (y retornar) como siendo simulacro" (DR, 92). La idea misma (la esencia) no es más que el efecto de una combinación finita de simulacros cuyas combinaciones son infinitas: "Cuando el eterno retorno es la potencia de ser (informal), el simulacro es el verdadero carácter o la forma de lo que es, del ente” (DR, 92).

Para poder pensar la diferencia en el tiempo, a Deleuze le ha sido preciso, pues - como puede apreciarse-, indagar a fondo el mecanismo de la repetición en su interpretación del pensamiento nietzscheano del eterno retorno (NP, 26): Y tal y como Deleuze lo entiende, el eterno retorno se convierte en "la ley de un mundo sin ser, sin unidad y $\sin$ identidad ${ }^{4}$. Un mundo que es "en intensidad, un mundo de diferencias, que no supone ni lo uno ni lo mismo, sino que se construye sobre la caída del Dios único y sobre la ruina del yo idéntico... Un mundo de fluctuaciones intensas, donde las identidades se pierden y donde cada uno no puede quererse más que queriendo también todas las demás posibilidades, haciéndose innumerables otros y aprendiéndose como un momento fortuito, cuyo azar mismo implica la necesidad de toda la serie entera ${ }^{5}$. A A pensamiento clásico de la representación y su coherencia sustituye la afirmación del caos. Esto es lo que vincula el eterno retorno nietzscheano a la problemática deleuziana del simulacro y de la destrucción de las copias icónicas, pues, como queda dicho, lo que retorna en el eterno retorno es siempre lo que difiere. Para Deleuze, en ello radica la diferencia del eterno retorno de Nietzsche del de los antiguos, que era retorno de lo mismo o del todo.

Deleuze insiste en la diferencia de naturaleza que separa la copia y el simulacro, y protesta contra su confusión como meras diferencias de grado (DR, 382; Cfr. también LB, 10-13). Para él, la copia se define por su grado de semejanza con el modelo, mientras el simulacro se caracteriza por sus meros efectos externos de semejanza. Invertir el plantonismo es también, consiguientemente, acabar con esta maldición del simulacro afirmando la "potencia positiva" que le confiere su "carácter demoníaco" (LS, 302-3; DR, 355-6). Es hacer de la semejanza el efecto externo del simulacro, y de la identidad la semejanza que se dice a partir de la afirmación de la diferencia entre series heterogéneas.

5 Ibid., pág. 283. 
De hecho, sustraído el poder de otorgar el sentido a los fenómenos al trasmundo de la metafísica - como mundo de las esencias inteligibles-, ahora es el eterno retorno mismo el que se convierte en "potencia de ser»: "La cosa es el simulacro mismo, el simulacro es la forma superior, y lo difícil para toda cosa es alcanzar su propio simulacro, su estado de signo en la coherencia del eterno retorno" (DR, 93). Pero, ¿cómo una cosa, o un yo, alcanzan su propio simulacro? ¿Cuál es el proceso que permite a una significación formarse y desaparecer en el ćrculo de la proposición, gracias a la producción del sentido/no sentido?

En el caso de la identidad del yo, su dependencia del eterno retorno se pone de manifiesto en el hecho de que éste se conciba, en el pensamiento de Nietzsche, como una revelación y no como el resultado teórico de un proceso de reflexión o de investigación. La revelación del eterno retorno es, según Deleuze, el instante en el que el yo percibe su ser como siendo producido por la sucesión y el devenir de identidades previas ya queridas. La identidad actual del yo sería, por tanto, la imagen del llegar a ser otro de todas las diferentes identidades que le han precedido en otros diferentes estados anímicos de revelación, y que han sido necesariamente olvidadas. Y puesto que el ser del yo actual es un convertirse en otro, querer ser yo, querer la potencia, es querer convertirse en otro distinto a ese yo de la memoria y de la revelación en el movimiento de la diferencia y de la repetición. Siguiendo a Klossovski ${ }^{6}$, Deleuze observa que la coherencia del pensamiento puro excluye al yo mismo en el momento en que se piensa. Por eso el yo quiere el olvido, o sea, el devenir puro, que le ofrece de nuevo la serie de todas las identidades posibles, cuyo retorno sólo se produce en el instante de la revelación.

En resumen, la afirmación de la identidad del yo es simultánea a la afirmación del devenir, que es el modo de expresarse de la voluntad de poder afirmativa, la cual rechaza cualquier meta que le hubiera sido impuesta por la memoria de un yo estático. De ahí que la voluntad de poder afirmativa quiera el olvido, siendo ella la que lanza los dados y afirma el azar. El yo renuncia a ser uno y el mismo de una vez por todas, y quiere la necesidad del movimiento circular. Esta es la razón de por qué el eterno retorno, en el pensamiento de Nietzsche, es un principio selectivo que ofrece el criterio riguroso a la voluntad para distinguir las fuerzas activas y reactivas, y para operar la transformación de

6 KLossovsk1, P., Nietzsche et le cercle vicieux, París, Mercure de France, 1969. Cfr. también, de este mismo autor, Simulacra, Berna, Kunshalle, 1981. 
las segundas en las primeras, haciendo posible la inversión de la negación como cualidad de la voluntad de poder nihilista en potencia de afirmación.

A la vez, esta ruina de la noción clásica de sujeto como identidad estable es indisociable de la disolución del objeto como polo estable en la relación de conocimiento. Para aparecer, la significación debe pasar necesariamente por todas las identidades posibles a otras significaciones que la harán retornar siempre la misma en el instante de la comprensión. De ahí la ilusión que supone la creencia en la estabilidad del referente y en la firmeza de lo que separa a lo verdadero de lo falso. Querer es siempre, sin embargo, un querer de nuevo, por lo que el ser del devenir es un retornar de lo mismo en la voluntad de poder como efecto de una potencia diferenciadora. Lo mismo no retorna, por tanto, eternamente más que por la diferencia diferenciadora, o sea, por la potencia que marca sin cesar la diferencia. En conclusión, el universo no es más que un movimiento de continua huída de sí mismo para reencontrarse de nuevo en la producción inagotable de lo múltiple y de lo diferente.

\section{Lo trágico como fundamento de una ética afirmativa}

Lo trágico es «el método del eterno retorno, método pluralista, diferencial, tipológico y genealógico" (NP, 122). En Nietzsche, el desarrollo de la oposición entre espíritu trágico y decadencia sirve de trasfondo al ejercicio crítico de la genealogía, que pretende recuperar el sentido de la repulsa sofista a la pregunta socrática sobre el ser para hacer depender tal pregunta de la relación entre fenómeno, fuerza que se apodera de él y voluntad de poder que califica la fuerza como afirmativa o negativa. Así, el método nietzscheano abre el horizonte de una ciencia activa que asume el perspectivismo y que se basa en la experiencia de que toda verdad no es más que una interpretación y todo conocimiento una ilusión. Para esta ciencia, vertebrada sobre el método del eterno retorno, no se podrá interpretar ninguna verdad, ningún valor, ningún texto o signo sin situarlo en la relación de fuerzas que lo condicionan y dentro de la línea temporal que caracteriza su plano de expresión.

Pero lo que propiamente caracteriza a lo trágico, en el planteamiento de Nietzsche, es la afirmación de la vida que opone, a la dialéctica de la mediación, la irreductibilidad de las oposiciones. Afirmación de la vida, no como vida humana para hacer del hombre el punto de referencia último de los valores y la medida de todas las cosas, sino afirmación de una vitalidad imperso- 
nal, cósmica y más originaria que la que aflora en la conciencia (potencia reactiva que niega la vida en vez de acrecentarla): «No se ha comprendido que lo trágico era pura y múltiple positividad... La afirmación es lo trágico, pues afirma el azar y, del azar, la necesidad" (NP, 66). Esta es la gran diferencia de Nietzsche respecto de todos los demás pensadores trágicos de la modernidad: Pascal, Schopenhauer, Kierkegaard, Chestov, que dan a lo trágico como desenlace el ascetismo, y, por tanto, la negación de lo múltiple y del azar: «No se ha comprendido nada, según Nietzsche, sobre qué es lo trágico: trágico es igual a gozoson (NP, 41). Pues si la existencia consiste en esta relación de afirmación de la voluntad de poder como afirmación dionisíaca de la diferencia, es que es inocente, y debe interpretarse como un fenómeno estético y no moral, o como un juego en el que el lanzamiento de dados afirma el azar y la necesidad que procede de él. Según Nietzsche, «Heráclito es el pensador trágico, es aquél para quien la vida es radicalmente inocente y justa. Comprende la existencia a partir de un instinto de juego, hace de la existencia un fenómeno estético, no un fenómeno moral o religioso" (NP, 27). Por tanto, concluye Deleuze, a la construcción nietzscheana -en el plano teórico- de un pensamiento de la afirmación de lo múltiple, corresponde, en el plano práctico, una ética de la alegria de lo plural y lo diverso.

La base del pensamiento trágico es, pues, la afirmación de la vida y el rechazo de la mediación entre las contradicciones, pero sin caer en el pesimismo del hombre que se ve privado de vías de salvación porque no consigue superar lo negativo. En este sentido, el pensamiento trágico es lo opuesto a la dialéctica hegeliana: «El superhombre se levanta contra la concepción dialéctica del hombre, y la transvaloración contra la dialéctica de la apropiación o de la supresión de la alienación... El antihegelianismo atraviesa la obra entera de Nietzsche» (NP, 9). Las contradicciones, como elemento propio de la dialéctica (que se apoya en lo negativo para construir la afirmación como negación de la negación), no forman parte, para el Nietzsche interpretado por Deleuze, de la tragedia, sino que son ingredientes más propios del drama. Esto hace que creadores como Wagner o Schopenhauer no puedan ser considerados por Nietzsche como trágicos sino, a lo sumo, como dramáticos. La tragedia no es, para él, negación de la negación, sino directamente afirmación. No está animada por el resentimiento, sino que es expresión de una actitud gozosa. $\mathrm{O}$ dicho en otras palabras, no se basa en la superación de lo negativo sino en la aceptación del devenir, que Nietzsche no quiere conciliar en una síntesis última y mediadora, sino que es asumido en su atomística multiplicidad. 
No obstante, Nietzsche no llega a definir en estos términos lo característico de su pensamiento trágico hasta la etapa de madurez de su trayectoria filosófica, debatiéndose en su obra de juventud - sobre todo en El nacimiento de la tragedia- por desvincular su intuición original de las dependencias expresivas del lenguaje schopenhaueriano. Aún así, ya en sus primeras obras se advierten las líneas de fuerza que acabarán imponiéndose en los desarrollos posteriores. Por ejemplo, Deleuze subraya cómo, ya en El nacimiento de la tragedia, es Apolo quien, para Nietzsche, crea la forma y la expresión de la tragedia por la objetivación de un fondo dionisíaco: «Apolo es quien desarrolla lo trágico en drama, quien expresa lo trágico en un drama. La tragedia es el coro dionisíaco que se distiende proyectando fuera de él un mundo de imágenes apolíneas... En el curso de muchas explosiones sucesivas, el fondo primitivo de la tragedia produce un sueño. El drama es, pues, representación de nociones y de acciones dionisíacas, la objetivación de Dionisos bajo una forma y en un mundo apolíneos" (NP, 14).

Lo que se pone de manifiesto en este texto es una determinada relación de Apolo y Dionisos en la configuración de la tragedia, necesitada de una posterior transformación o reformulación. Pues esta primera visión, como el mismo Nietzsche reconoce, "desprende un repugnante olor hegeliano ${ }^{7}$. Deleuze resume así sus tres características más importantes: «1) La contradicción, en $E l$ nacimiento de la tragedia, es la de la unidad primordial y la individuación, del querer y de la apariencia, de la vida y del sufrimiento. Esta contradicción original hace de testigo contra la vida, ocupa la vida; la vida necesita ser justifica$\mathrm{da}$, es decir, redimida del sufrimiento y de la contradicción; 2) La contradicción se refleja en la oposición entre Apolo y Dionisos. Apolo diviniza el principio de individuación, construye la apariencia de la apariencia, la bella apariencia, el sueño o la imagen plástica, y se libera así del sufrimiento... Dionisos, por el contrario, retorna a la unidad primitiva, destroza al individuo, lo arrastra al naufragio y lo absorbe en el ser original; 3) La tragedia es reconciliación, esta alianza admirable y precaria dominada por Dionisos. Porque en la tragedia Dionisos es el fondo de lo trágico" (NP, 13).

$\mathrm{El}$ aspecto más discutible de toda esta visión es esta conclusión de que la tragedia es reconciliación. Para el Nietzsche maduro, la tragedia mantiene la unidad de las dos series heterogéneas simbolizadas por lo apolíneo y lo dioni-

7 Nietzsche, F, Ecce homo, trad. cast. A. Sánchez Pascual, Madrid, Alianza, 1978, pág. 68. 
síaco sin mediarlas ni conciliarlas, gracias al concepto del eterno retorno. La tragedia es, así, una fuerza de "entre dos», una fuerza de doble rostro cuya creatividad encuentra su potencia precisamente en la constitución del problema de la divergencia y de la diferencia. De ahí su valor como pensamiento que traduce, que asegura el paso creando conceptos entre dos series. O sea, de ahí su condición de pensamiento que inter-preta. Es la dualidad que, inseparable del esfuerzo de invención que implica toda interpretación, caracterizará, en el pensamiento de Deleuze, al esquizoanálisis. Por otra parte, El nacimiento de la tragedia no ofrece más que un esbozo de Dionisos como dios afirmativo y afirmador, siendo sólo después cuando esta caracterización del dios de lo excesivo se una con la de la conquista de las apariencias y el reconocimiento de la positividad del simulacro.

De todos modos, ya en esta primera obra de juventud, Nietzsche intuye que la verdadera oposición no es, para él, la de Apolo y Dionisos, sino la de Dionisos y Sócrates: "Sócrates es el primer genio de la decadencia. Opone la idea a la vida y juzga la vida por la idea; plantea la vida como debiendo ser juzgada, justificada por la idea. Nos pide llegar a sentir que la vida, aplastada bajo el peso de lo negativo, es indigna de ser deseada por ella misma... Sócrates es el hombre teórico, el único verdadero contrario del hombre trágico» (NP, 15). El hombre teórico es el que elabora conceptos y objetos para y por el pensamiento dogmático y la representación estática, sofocando lo múltiple y debilitando la vida.

\section{El pensamiento sin imagen y la nueva imagen del pensamiento}

Lo propio del eterno retorno como método del pensamiento trágico es, pues, oponer, por un lado, la genealogía a la trascendentalidad, y, por otro, el pensamiento a la razón, imponiendo una concepción nueva del irracionalismo. Esto no significa rechazar la racionalidad, sino promover un nuevo pensamiento crítico a partir del reconocimiento de los aspectos perversos contenidos en la visión dogmático-racionalista del pensamiento: «Nos equivocamos sobre el irracionalismo cuando creemos que esta doctrina opone a la razón algo que no sea pensamiento: los derechos de lo dado, del corazón, del capricho o de la pasión. En el irracionalismo no se trata de otra cosa que del pensamiento y del pensar. Lo que se opone a la razón es el pensamiento mismo. Lo que se opone al ser razonable es el pensador mismo. Visto que la razón se ocupa de 
recoger y expresar los derechos de lo que somete al pensamiento, el pensamiento reconquista sus propios derechos y se hace legislador contra la razón" (NP, 107).

Oponer la genealogía a la trascendentalidad es tratar de sustituir las instancia reactivas de la conciencia y de la razón por la afirmatividad de la voluntad de poder, que en lugar de adherirse a los valores transmitidos e impuestos y trabajar en favor de su preservación, busca crear otros nuevos más en conexión con una nueva sensibilidad: «El objetivo de la crítica no son los fines del hombre o de la razón, sino el superhombre, el hombre superado. En la crítica no se trata de justificar, sino de sentir de otro modo, otra sensibilidad" (NP, 108). Es esta transvaloración la que exige una modificación sustancial de la concepción tradicional del pensamiento y de la inteligencia, considerados como la función que permite fijar los movimientos de la vida en una representación, partiendo de la cual el hombre puede actuar en el mundo y satisfacer unas necesidades dentro de un orden social determinado.

Siguiendo de cerca ciertas ideas de Bergson, Deleuze denuncia la complicidad del concepto tradicional de inteligencia con el predominio exclusivo de las representaciones espaciales $y$, por tanto, la imposibilidad de pensar en términos de duración: «Bergson cuestiona el orden de las necesidades, de la acción y de la sociedad, que nos inclina a retener de las cosas sólo lo que nos interesa; cuestiona el orden de la inteligencia en su afinidad natural con el espacio; y cuestiona el orden de las ideas generales que acaban por recubrir las diferencias de la naturaleza" (LB, 25). Como es sabido, Bergson contrapone a la metafísica de la sustancia su concepción del flujo o impulso vital desde el que comprende el devenir de la vida como energía creadora, sustituyendo el dinamismo de ésta a las viejas esencias estáticas de la metafísica. Su método es la intuición, una operación que permite dividir los mixtos que nos ofrece la experiencia y apreciar las diferencias de naturaleza, sin confundirlas con meras diferencias de grado: "Se trata siempre, según Bergson, de dividir un mixto siguiendo sus articulaciones naturales" ( $\mathrm{LB}, 11)$. Y es frente a este método frente al que la estupidez de la inteligencia tradicional proclama que "todo es equivalente».

Lo importante, y también lo más característico del funcionamiento de la inteligencia está, para Deleuze, en su capacidad inventiva y creativa, en una cierta libertad para plantear problemas más que para descubrir o reconocer soluciones: "Plantear el problema no es sólo un descubrir, sino un inventar. El descubrimiento lleva sobre lo que ya existe, actual o virtualmente, y que llega- 
rá con seguridad antes o después" (LB, 11). Porque si el pensamiento tiene la capacidad de explicar un signo, de desarrollarlo en una idea, es porque la idea se encuentra ya en el signo, envuelta y oculta en él, o sea, en ese estado latente $y$ ambiguo que obliga a pensar. De ahí que, para Deleuze, las obras de arte puedan contener, desde este punto de vista, una potencialidad de pensamiento mucho mayor que los sistemas filosóficos. Si el pensamiento debe ser entendido como facultad de plantear problemas, en general, más que de resolverlos, entonces es preciso reconocer que la obra de arte tiene cierta superioridad en la actividad noética de búsqueda de las esencias: "La filosofia, con todo su método y su buena voluntad, no es nada frente a las presiones secretas de la obra de arte. La creación, lo mismo que la génesis del acto de pensar, parte siempre de los signos. La obra de arte nace de los signos tanto como ella los hace nacer. El creador es como un divino intérprete que mira los signos en los que se trahiciona la verdad" (PS, 119). Pues la obra de arte, al provocar encuentros con signos inmateriales, crea acontecimientos cuyos efectos pueden revelarnos la unidad del estilo, del sentido y de la esencia, haciendo actuar en la superficie la diferencia última y absoluta ${ }^{8}$.

El nuevo pensamiento crítico sustituye, en definitiva, las categorías y las clasificaciones estáticas - fijadas en la identidad que se deriva de la repetición de lo mismo, de lo semejante y de lo idéntico-, por la diferencia y la repetición del pensamiento sin imagen, siempre dinámico, un pensamiento del acontecimiento puro tal como Deleuze se esfuerza en describirlo en Lógica del sentido. Este pensamiento se autoconcibe como tarea de interpretación y evaluación, más acá de la verdad del texto y de su significado, de las relaciones de fuerza que se actualizan en la obra y que conducen a un determinado modo de redistribuir y aplicar el lenguaje. Interpretación de la que no escapa la misma interpretación de la tradición filosófica, en la que hay que averiguar qué fuerzas la determinan, activas o reactivas, con el fin de saber qué sentido se tiende a dar a las cosas. En definitiva, la interpretación, como desciframiento, explicación o traducción de signos a partir de las relaciones de fuerza que los sos-

8 La unidad de la obra de arte se caracteriza por la diferencia en acto, o sea por esa potencia de doble cara a cuya reconsideración Deleuze vuelve una y otra vez. Por otra parte, la centralidad aquí del concepto de estilo está en función de su condición de procedimiento por el que algo alcanza su propio simulacro. Para una ampliación del pensamiento estético de Deleuze, es muy sugerente el estudio de BuYDens, M., Sahara: L'esthètique de Gilles Deleuze, París, Vrin, 1990. 
tienen, es inseparable de ese esfuerzo de invención que Deleuze caracteriza como arte de adivinar las superficies: «La interpretación adivinatoria consiste en la relación entre acontecimiento puro (todavía no efectuado) y la profundidad de los cuerpos, las acciones y las pasiones corporales de donde resulta. $Y$ se puede decir precisamente cómo procede esta interpretación: se trata de cortar el espesor, de tallar las superficies, de orientarlas, de agrandarlas y multiplicarlas, para seguir el trazado de las líneas y de las rupturas que se dibujan sobre ellas. Así dividir el cielo en secciones y distribuir las líneas de los movimientos de los pájaros, seguir sobre el suelo la letra que traza el grunido de un cerdo, sacar el hígado a la superficie y observar sus líneas y fisuras. La adivinación es, en el sentido más general, el arte de las superficies, de las líneas y puntos singulares que alli aparecen" (LS, 168). La crítica afirmativa es, en fin, la crítica que se apoya en las líneas de divergencia para no considerar las repeticiones sino como efectos inseparables de la diferenciación, de lo que hace la diferencia y del movimiento de los simulacros.

Toda esta contraposición entre razón y pensamiento impone así una nueva imagen del pensamiento que recupera la relación presocrática entre pensamiento y vida, en la forma de una coacción de ésta sobre aquél que lo obliga a pensar y lo enfrenta continuamente con las convenciones vigentes. En este sentido, el nuevo pensamiento se autoposiciona en la inactualidad, o sea, en la tesitura de la creación de valores «eternamente nuevos, eternamente intempestivos, siempre contemporáneos a su creación, transhistóricos, suprahistóricos, y que... testimonian un caos genial, desorden creador irreductible a todo orden. Es el caos del que Nietzsche decía que no era lo contrario del eterno retorno, sino el eterno retorno en persona. De este fondo suprahistórico, de este caos intempestivo, parten las grandes creaciones 9 ". Por ello, este pensamiento no puede concebir la verdad sino apoyada en una tipología pluralista de las fuerzas y, por tanto, desde las categorías de sentido y valor, y no desde la distintición de verdadero y falso; ni puede reconducir la verdad a la representación, que implica el reconocimiento de lo existente en sí y, por tanto, la reducción de la voluntad de poder a voluntad de atribuirse los valores comunes, o sea, a conformismo. La representación es esencialmente reactiva, la determina el resentimiento en cuanto sentimiento de la reactividad de una fuerza que, en lugar de expresar su potencia de manera activa, se interioriza, se

9 Deleuze, G., «Conclusions...», ed. cit., pág. 286. 
vuelve contra sí y da forma a su sentimiento de culpa y de responsabilidad, incompatible con la afirmación de la inocencia de la vida característica de lo trágico.

En el pensamiento reactivo, propio del nihilismo, la diferencia originaria que se establece entre las fuerzas es sustituída por la sustancialización moral de lo bueno y lo malo. Lo que predomina es la negación, fruto del miedo y la debilidad de una fuerza que, incapaz de afirmar su propia diferencia, en lugar de actuar, reacciona a la defensiva contra las fuerzas por las que no quiere ser dominada agitando contra ellas los fetiches del bien en sí y el mal en sí. Por ello, el pensamiento reactivo rechaza la genealogía, o sea, los mecanismos diferenciales que dan cuenta de las fuerzas, y a ella le sustituye la oposición como su figura invertida y abstracta, poniéndose así de manifiesto «el pensamiento del hombre teórico en conflicto con la vida, pretendiendo juzgarla, limitarla y medirla" (NP, 266). Frente a la síntesis del eterno retorno, "el nihilismo considera el devenir como algo que debe expiar y que debe ser reabsorbido en el ser, y considera lo múltiple como algo injusto que debe ser juzgado y reabsorbido en lo uno" (NP, 36).

Por eso, la superación del nihilismo planteada por Nietzsche, que no sería otra cosa que la reconversión de las fuerzas reactivas en activas, comporta la recuperación, no sólo del análisis genealógico de la voluntad de poder en el plano de la teoría, sino también el elemento práctico de la afirmación de lo múltiple, del devenir y de la diferencia. Para Deleuze este transvaloración, este salto no podría consistir nunca en una inversión dialéctica, pues en el horizonte teórico de ésta no caben la afirmación dionisíaca ni la figura del superhombre, pero, sobre todo, porque la transvaloración nietzscheana hace de lo negativo (la destrucción de los valores del nihilismo) un momento de la afirmación.

\section{Referencias bibliográficas}

Baudrillard, J., Oublier Foucault, París, Galilée, 1977, págs. 21-41.

Boundas, C.V.-OlKowsKa, D. (eds.), Gilles Deleuze and the theater of philosophy, Londres, Routledge, 1994.

CACCIARI, M., "Razionalità e irrazionalità nella critica del politico in Deleuze e Foucault», en Aut Aut 1977 (161), págs. 119-133. 
Clément, C., Miroirs du sujet, París, 10/18, 1975, págs. 163-182: "L'incarnation fantasmatique».

ClousCaRd, M., Néo-Fascisme et idéologie du désir: Les Tartuffes de la révolution; París, Denoël, 1973.

Colombat, A., Deleuze et la litterature, New York, Lang, 1990.

Cressole, M., Deleuze, París, Ed. Universitaires, 1973.

Delauney, M. B., “Deleuze et Nietzsche», en Magazine Littéraire 1988 (257), págs. 44-46.

Delco di Bellinzona, A., Filosofia della differenza: La critica del pensiero rappresentativo in Deleuze, Locarno, Pedrazzini, 1988.

Delco di BellinzonA, A., "Deleuze: Dalla metafisica della copia alla teoria del simulacro», en Rivista di Estetica 1988 (28-30), págs. 54-63.

Douglas, P., "Deleuze's Bergson: Bergson redux”, en BuRWICK, F.-DOUGLAS, P. (eds.), The Crisis in Modernism: Bergson and the Vitalist Controversy, Cambridge, Cambridge Univ. Press, 1992.

Dumollue, C., Nietzsche et Artaud: pour une éthique de la cruanté, Paris, Presses Universitaires, 1992.

DumonCEL, J.C., «Deleuze, Platon et les poètes», en Poétique 1984 (59), págs. 369387.

FEDIDA, P., Le concept et la violence, París, UGE, 1977.

FERRARIS, M.-AGOSTINI, D., «Proust, Deleuze et la répetition. Notes sur les niveaux narratifs d' $A$ la recherche du temps perdios, en Litterature 1978 (VIII:32), págs. 66-85.

FERRARIS, M., "Deleuze. Critica, affirmatività, sperimentazione», en Aut Aut 1982 (187-188), págs. 123-136.

GlucksmanN, A., "Préméditations nietzschéennes", en Critique 1965 (213), págs. 125-144.

HARDT, M., Gilles Deleuze: an apprenticeship in Philosophy, Minneapolis, Univ. of Minnesota Press, 1995.

LARUELlE, F., Les philosophies de la différence, París, PUF, 1986.

LEIGH, J. A., "Deleuze, Nietzsche and the Eternal Return", en Philosophy Today 1978 (22), págs. 206-223.

Martin, J. C., Variations. La philosophie de G. Deleuze, Payot, París, 1993.

MARTINEZ, F. J., Ontologia y diferencia, Madrid, 1986.

Mengue, PH., Gilles Deleuze ou le systeme du multiple, París, Ed. Kimé, 1994. 
Olabuenaga, A., "Gilles Deleuze: Por una filosofía de la disolución", en Revista de Occidente 1986 (56), págs. 27-34.

PARDO, J. L., Deleuze: violentar el pensamiento, Madrid, Cincel, 1990.

PeCORA, V. P., "Deleuze's Nietzsche and Post-Structuralist Thougth", en Substance 1986 (48), págs.34-50.

Rella, F., Il mito dell'altro: Lacan, Deleuze, Foucault, Milán, Feltrinelli, 1978.

Rolland de Réneville, J., Itinéraire du sens, Paris, PUF, 1982.

RUSTICHELli, L., La profondita della superficie. Senso del tragico e giustificazione estetica dell'esistenza in Nietzshce, Milán, Mursia, 1992.

VACCARO, G.B., Deleuze e il pensiero del molteplice, Milán, Franco Angeli, 1990.

WAHL, J., "Nietzsche et la philosophie», en Revue de Mëtaphysique et Morale 1963 (3, July-Sept.), págs. 352-379.

ZourabichVIl, F., Deleuze, une philosophie de l'evenement, París, PUF, 1994. 